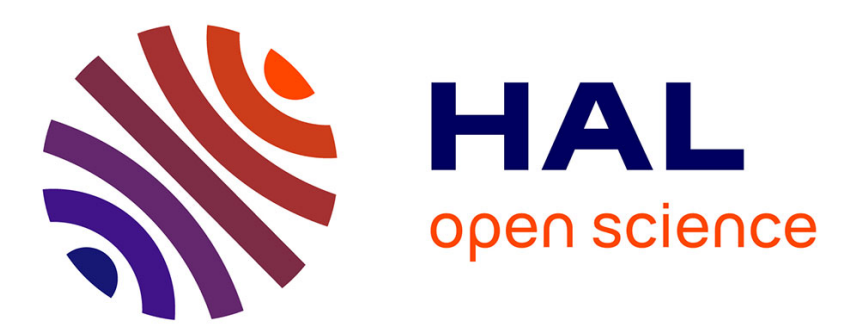

\title{
Waterborne Nanocomposites with Enhanced Breakdown Strength for High Energy Storage
}

Junjin Che, Wilfrid Neri, Isabelle Ly, Philippe Poulin, Cécile Zakri, Jinkai Yuan

\section{- To cite this version:}

Junjin Che, Wilfrid Neri, Isabelle Ly, Philippe Poulin, Cécile Zakri, et al.. Waterborne Nanocomposites with Enhanced Breakdown Strength for High Energy Storage. ACS Applied Energy Materials, 2020, 3 (9), pp.9107-9116. 10.1021/acsaem.0c01476 . hal-02950567

\section{HAL Id: hal-02950567 https://hal.science/hal-02950567}

Submitted on 28 Sep 2020

HAL is a multi-disciplinary open access archive for the deposit and dissemination of scientific research documents, whether they are published or not. The documents may come from teaching and research institutions in France or abroad, or from public or private research centers.
L'archive ouverte pluridisciplinaire HAL, est destinée au dépôt et à la diffusion de documents scientifiques de niveau recherche, publiés ou non, émanant des établissements d'enseignement et de recherche français ou étrangers, des laboratoires publics ou privés. 


\title{
Waterborne Nanocomposites with Enhanced Breakdown Strength for High Energy Storage
}

Junjin Che, Wilfrid Neri, Isabelle Ly, Philippe Poulin, Cécile Zakri, Jinkai Yuan*

Centre de Recherche Paul Pascal, CNRS, Université de Bordeaux, 115 Avenue Schweitzer, 33600 Pessac, France

*Correspondence to: jinkai.yuan@crpp.cnrs.fr

\begin{abstract}
Polymers have been considered as promising materials for dielectric energy storage because of their high breakdown strength, favorable flexibility and processability. The achievable energy density of polymers is however limited by their intrinsic low dielectric constant. Until today, most of them are either melt-extruded at high temperatures or solutionprocessed in harmful organic solvents. Making high-energy polymeric dielectrics via environmentally friendly manners has been a long standing challenge. Herein, a water-based technique is employed to prepare all-polymeric dielectrics consisting of poly(vinylidene fluoride) (PVDF) latex nanoparticles dispersed within a polyvinyl alcohol (PVA) matrix. These waterborne nanocomposites, processed at low temperature, demonstrate great promise in resolving the paradox between dielectric constant and breakdown strength. A high energy density of $8.1 \mathrm{~J} / \mathrm{cm}^{3}$ is thus achieved at $\sim 515 \mathrm{MV} / \mathrm{m}$, which is $300 \%$ greater than that of each polymer component. Moreover, with an appropriate load resistance, the nanocomposite can release the stored energy at a rate of microseconds, giving rise to a power density of 1.13 $\mathrm{MW} / \mathrm{cm}^{3}$ that is nearly $400 \%$ higher than that of benchmark biaxial oriented polypropylene dielectric films.
\end{abstract}

KEYWORDS: waterborne nanocomposite, polymer latex, energy density, power density, breakdown strength 


\section{INTRODUCTION}

Energy storage technologies have been pursued to improve the grid scale load leveling for instantaneous and periodic fluctuations, particularly with ever-increasing production of renewable energy that heavily relies on meteorological conditions. ${ }^{1-3}$ Current technologies, such as lithium-ion batteries and supercapacitors, have high gravimetric energy density but are unable to provide extremely rapid response to the peaks in energy production or demand. Stabilizing the load on the grid scale requires energy storage devices with very fast energy uptake and delivery. Dielectric capacitors store energy electrostatically in the form of electric displacement induced by the applied electric field. This energy storage mechanism offers intrinsically high power density, high operating voltage, and long work lifetime ${ }^{4-7}$. However, such mechanism also causes limited energy densities that are approximately three orders of magnitude less than fuel cells or Li-ion batteries. ${ }^{8,9}$ Such limitation requires greater amount of materials to be used, and makes this approach more costly. Therefore, developing dielectric materials with improved energy density is imperative to enable the continuous miniaturization and increased functionality of the cutting-edge electrical power systems. Generally, the energy density $U_{e}$ of dielectrics is determined by the applied electric field $E$ and the associated electric displacement $D .^{2}$ It can be mathematically expressed by

$$
U_{e}=\int_{D_{\max }}^{0} E d D
$$

Therefore, the key to improve the energy density of dielectric materials is to achieve a high breakdown strength $E_{\mathrm{b}}$ (the maximum electric field that the material can withstand without undergoing electrical breakdown) and a large electric displacement $D_{\max }$.

Compared with inorganic dielectrics, polymers are attractive due to their high breakdown strengths, low losses, flexibility and ease of processing. ${ }^{10-13}$ Until today, many polymers, such as biaxial oriented polypropylene (BOPP), polyethylene terephthalate (PET), polycarbonate (PC) and polyvinyl alcohol (PVA), have been deployed to make film capacitors. ${ }^{2,10,14}$ However, the low dipole moments of the chemical bonds in these polymers result in low dielectric constant $(k<4)$, leading to a low energy density $\left(<5 \mathrm{~J} / \mathrm{cm}^{3}\right)$ even under the electric field near breakdown strengths. Conversely, polar polymers, such as poly(vinylidene fluoride) (PVDF)based ferroelectric polymers, are particularly promising for energy storage due to the high polarization of the $\mathrm{C}-\mathrm{F}$ bonds and the spontaneous orientation of dipoles in the crystalline domains. ${ }^{15,16}$ However, the strongly coupled dipoles and large ferroelectric domains in these polymers cause high energy barriers for ferroelectric switching, leading to pronounced hysteresis loops and in turn to low charge/discharge efficiency (the ratio of $U_{e}$ to the total stored 
energy density). Chemical methods (i.e., copolymerization) or high-energy radiation have been developed to increase the efficiency by limiting ferroelectric losses of PVDF based polymers through changing the ferroelectric polymers into relaxor-ferroelectric ones. ${ }^{17,} 18$

In spite of the intrinsic improvements of energy density by modifying macromolecular structures, most of efforts have been devoted, in the past decades, to the composite approach, a more versatile extrinsic strategy. $2,10,11,19,20$ This approach capitalizes upon the combination of different components/phases with high dielectric strength and high dielectric constant respectively via engineering their interfaces or interphases. ${ }^{21-26}$ Indeed, a large number of ceramic nanoparticles with different dimensionalities, such as highly polarizable $\mathrm{BaTiO}_{3}$ nanoparticles or nanofibers ${ }^{27}$, or high- $E_{\mathrm{b}}$ boron nitride nanosheets ${ }^{8,28}$, have been added to PVDF-based polymers to achieve concomitant enhancement of dielectric constant and breakdown strength. Nevertheless, the high density of ceramics and the inorganic/organic discrepancy in physicochemical properties usually lead to sedimentation and unexpected inhomogeneous distribution of nanofillers. ${ }^{29}$ This actually poses a great challenge on the mass production of high-quality dielectric nanocomposite films.

Being parallel with the inorganic/organic approach, blending lightweight polymers with different polar groups on the side chains has been also explored. ${ }^{30-38}$ The similar solubility and chemical structure of polymers allows for easier processability and good adaptability to the rollto-roll stretching fabrication. For instance, high- $E_{\mathrm{b}}$ and low-loss linear dielectric polymers, such as $\mathrm{PET}^{38}$ and $\mathrm{PC}^{36}$, have been multilayered with PVDF-based polymers to serve as a barrier for the treeing propagation through the film thickness. This method largely suppresses the conduction losses, improves the breakdown strength, and eventually enhances the energy density. In addition to the layered 2-2 composite configuration, rubber nanoparticles ${ }^{33}$ and thermoplastic polyurethane (TPU) ${ }^{35}$ that bear high breakdown strength have been also introduced into PVDF matrix to formulate 0-3 nanocomposites with elevated energy density.

Here we propose another 0-3 nanocomposites that are waterborne and made by mixing PVDF latex and water soluble PVA. Being different from the continuous phase of PVDF in previously reported composites, the low-cost PVDF latex nanoparticles are adopted as discrete polarizable domains in high- $E_{\mathrm{b}}$ PVA matrix. The moderate permittivity and conductivity contrast between PVDF and PVA is expected to achieve less distorted local electric field. We found that the presence of small amount (3 wt $\%$ ) of PVDF nanoparticles within PVA matrix can concurrently increase the permittivity and breakdown strength from 6.9 to 8.0 and from 438 $\mathrm{MV} / \mathrm{m}$ to $515 \mathrm{MV} / \mathrm{m}$ respectively, giving rise to an energy density of $8.1 \mathrm{~J} / \mathrm{cm}^{3}$. Moreover, the nanocomposite can release the stored energy on a load resistor of $10 \mathrm{k} \Omega$ at a rate of 
microseconds, leading to a power density of $1.13 \mathrm{MW} / \mathrm{cm}^{3}$. Both of the energy and power density are nearly $400 \%$ greater than those of benchmark BOPP. The use of water-based techniques can provide the environmentally friendly aspect to both processes and consumption of current high-energy dielectric films.

\section{EXPERIMENTAL SECTION}

Materials. PVA was obtained from Sigma-Aldrich under the trade name of Mowiol 18-88 (CAS number: 9002-89-5) with a molecular weight $\mathrm{M}_{\mathrm{w}}=195000 \mathrm{~g} / \mathrm{mol}$ and a degree of hydrolysis of 99\%. PVDF latex was supplied by Arkema (Kynar Aquatec ARC Latex) with an initial concentration of solid content of $44 \mathrm{wt} \%$.

Fabrication of PVDF/PVA nanocomposites. PVA was first dissolved in deionized water at $95^{\circ} \mathrm{C}$ in an oven overnight, and then magnetically stirred at $300 \mathrm{rpm}$ for $2 \mathrm{~h}$ at room temperature. The solution was afterwards filtrated under vacuum to obtain a fully dissolved aqueous solution. The PVA concentration was measured at $10.3 \mathrm{wt} \%$. As schematically illustrated in Figure 1a, various amount of PVDF latex was mixed with the PVA solution by magnetic stirring at room temperature for $4 \mathrm{~h}$. The final solute concentration of different aqueous mixtures is kept at 1.1 wt $\%$ by adding different amount of deionized water. The final solid PVA nanocomposites possessed different PVDF contents. The nanocomposite films were prepared by a solutioncasting method. In detail, $5 \mathrm{ml}$ well-mixed solution was casted onto a petri dish of poly(methyl methacrylate). Water was then evaporated at $55^{\circ} \mathrm{C}$ for $90 \mathrm{~min}$ under an infrared light. The dry film was peeled off and put into vacuum oven at $110^{\circ} \mathrm{C}$ for $20 \mathrm{~h}$. The PVDF/PVA nanocomposite films are transparent (Figure 1b) and their thickness ranges from $15 \mu \mathrm{m}$ to 25 $\mu \mathrm{m}$.

Characterizations of PVDF/PVA nanocomposites. The dielectric properties of the films were recorded as a function of frequency (from $10^{-1} \mathrm{~Hz}$ to $10^{6} \mathrm{~Hz}$ ) at room temperature by an impedance analyzer (MaterialsMates 7260, Italia). The dielectric breakdown strength and electric polarization-electric field $(P-E)$ loops were measured at room temperature in silicone oil via a PolyK ferroelectric polarization loop and dielectric breakdown test system. Fast discharge experiments were carried out through a capacitor charge/discharge system (PolyK Technologies). Before the characterizations, each sample was coated with aluminum electrodes to ensure a good contact. Transmission electron microscopy (TEM) images of PVDF/PVA nanocomposites were taken via a Hitachi $\mathrm{H} 600$ microscope operating at $75 \mathrm{kV}$. To make samples for TEM characterizations, the pure PVDF latex or the mixed solutions with different mass ratios between PVDF latex and PVA solution were directly dropped on a carbon-coated 
copper films (200 mesh), which was followed by a room-temperature evaporation of water to formulate an ultrathin layer. Wide-angle x-ray diffraction (XRD) was tested on a Rigaku Nanoviewer (MicroMax 007HF) with a rotating anode coupled to a confocal Max-Flux ${ }^{\circledR}$ Osmic mirror operating at a wavelength of $1.5418 \AA$. The recorded spectra were corrected by subtraction of the reference noise. Differential scanning calorimetry (DSC) measurements were performed using TA Instrument Q2000 under dry nitrogen atmosphere. About $3 \mathrm{mg}$ specimens were heated from 30 to $250{ }^{\circ} \mathrm{C}$ at a rate of $10{ }^{\circ} \mathrm{C} / \mathrm{min}$ with three cycles, and the second curve was selected to analyze.

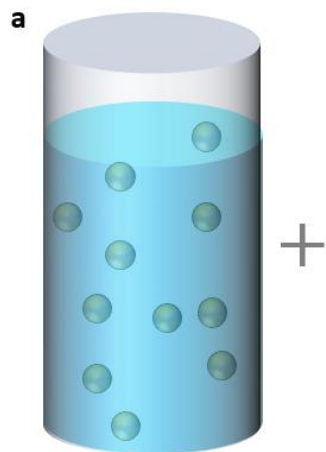

PVDF latex

b

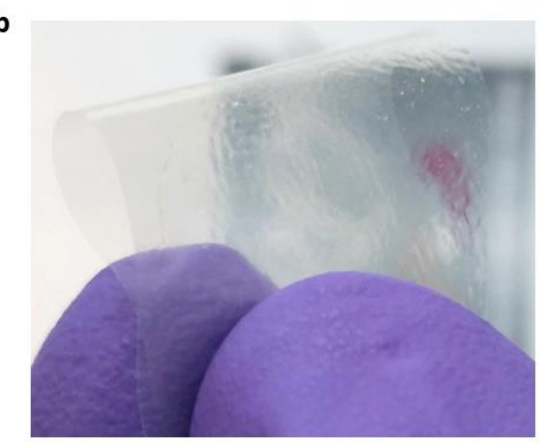

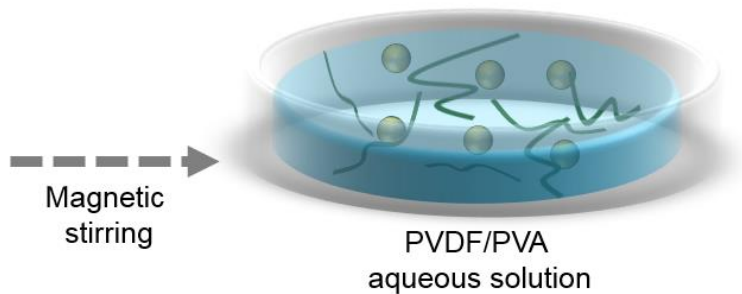

aqueous solution

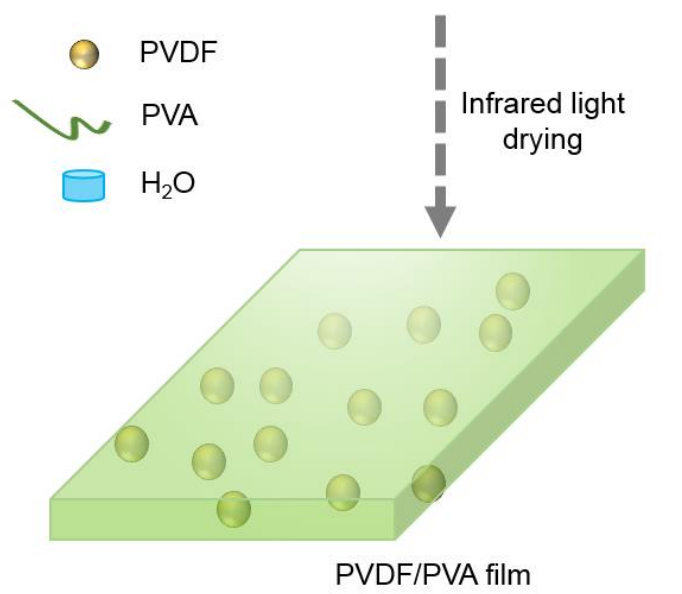

Figure 1. (a) Water-based processes to incorporate PVDF nanoparticles into PVA matrix and make dielectric nanocomposite films. (b) Photograph of a transparent PVA composite film filled with $3 \mathrm{wt} \%$ PVDF latex nanoparticles.

\section{RESULTS AND DISCUSSION}

Morphologies of PVDF latex and their nanocomposites. TEM was performed on pristine PVDF latex and their nanocomposites to investigate the dispersion state and the morphology of PVDF latex nanoparticles in PVA matrix. As shown in Figure 2a, PVDF latex particles are spherical with a diameter of $149 \mathrm{~nm}$. Figure $\mathbf{2 b - f}$ reveals the morphology evolution of nanocomposites with increasing the PVDF content from $1 \mathrm{wt} \%$ to $5 \mathrm{wt} \%$. At concentrations below $3 \mathrm{wt} \%$, the natural good dispersibility of PVDF particles can ensure the formation of isolated PVDF nanodomains in PVA matrix (Figure 2b-d). By contrast, as the concentration is 
beyond $4 \mathrm{wt} \%$, the particles start to coalesce and form clustering due to the attractive interactions (Figure 2e-f) during current water-based processing.
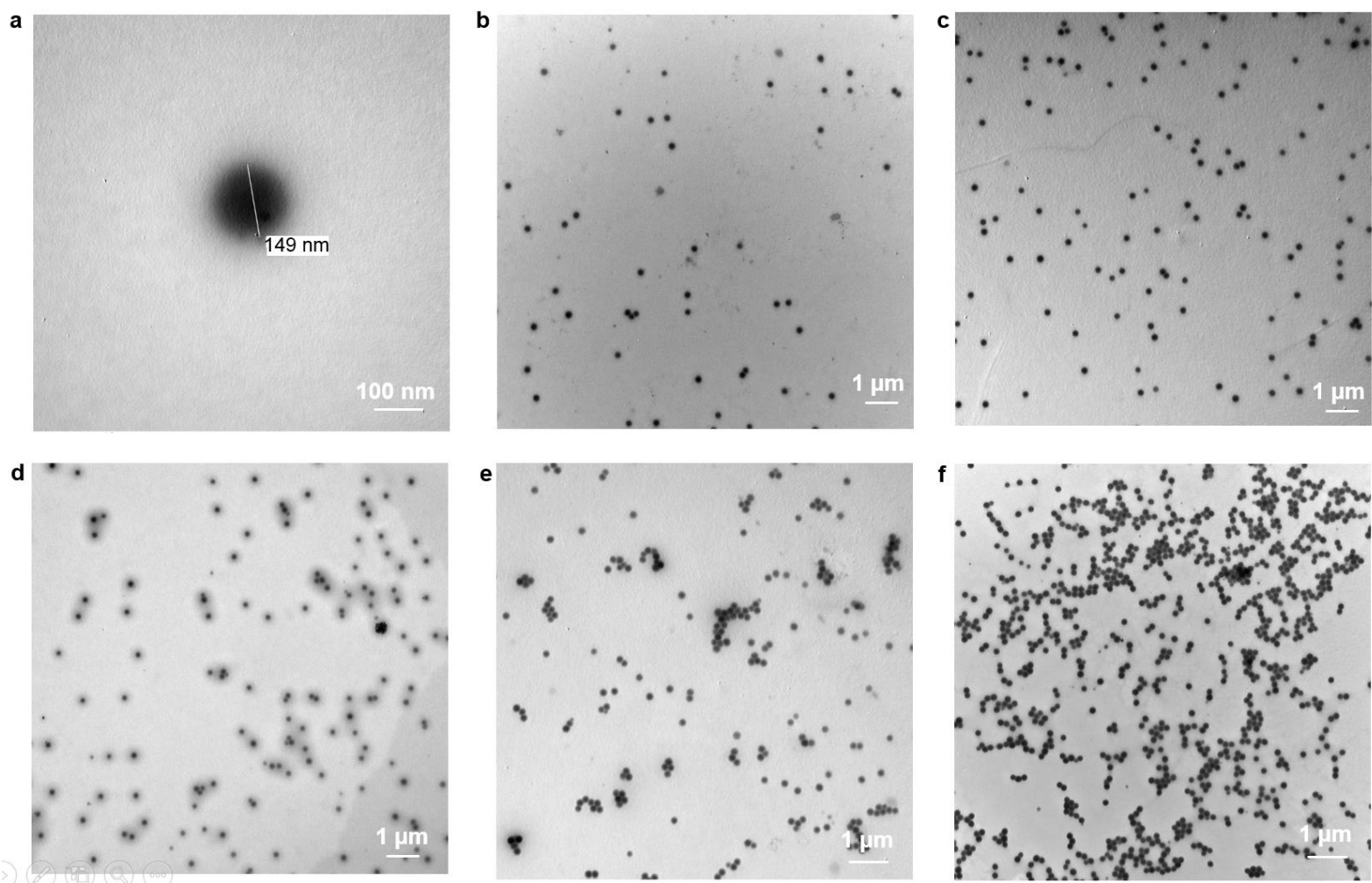

Figure 2. (a) TEM image of PVDF latex particle, showing a diameter of $149 \mathrm{~nm}$. TEM morphologies of PVDF/PVA nanocomposite films with various loadings of PVDF nanoparticles: (b) $1 \mathrm{wt} \%$, (c) $2 \mathrm{wt} \%$, (d) $3 \mathrm{wt} \%$, (e) $4 \mathrm{wt} \%$, and (f) $5 \mathrm{wt} \%$.

Dielectric performances of PVDF/PVA nanocomposite films. The dependences of dielectric constant on the frequency are shown in Figure 3a. Dielectric constants of all the polymer composites tend to decrease with increasing frequency. At each frequency, the dielectric constant increases monotonously with the PVDF content. Nevertheless, all the dielectric constants of composites fall into the interval of the two single polymer components. The conductivity and loss tangent are weakly affected by the presence of PVDF at frequencies beyond $100 \mathrm{~Hz}$ (Figure 3b-c). By contrast, differences of conductivity and losses are observed as the frequency decreases down to $100 \mathrm{~Hz}$ and below. The lowest conductivity and loss tangent are obtained at $3 \mathrm{wt} \%$ of PVDF nanoparticle. The variation of dielectric constant and losses with the concentration of PVDF nanoparticles is presented in Figure 3d. At $100 \mathrm{~Hz}$, the dielectric constant increases from 6.9 to 8.1. In spite of the enhancement in dielectric constant, the losses at $100 \mathrm{~Hz}$ keep stable with varying PVDF content and remain at a level below 0.05. 

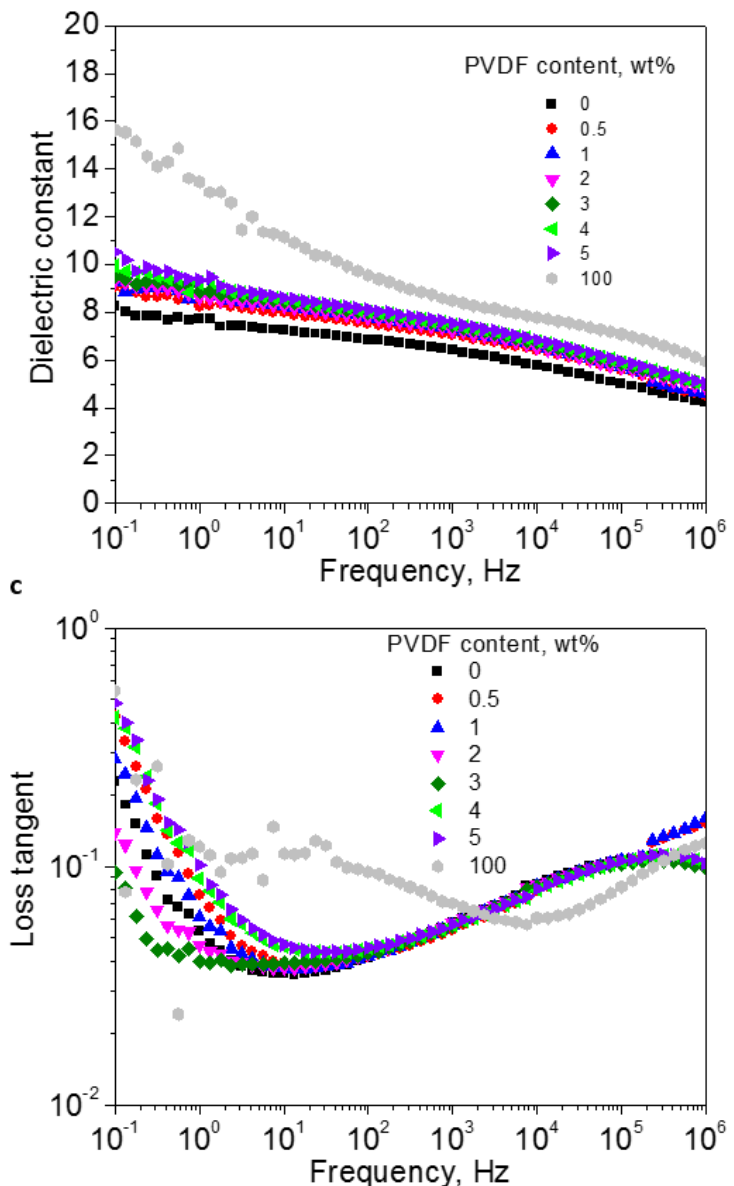

b
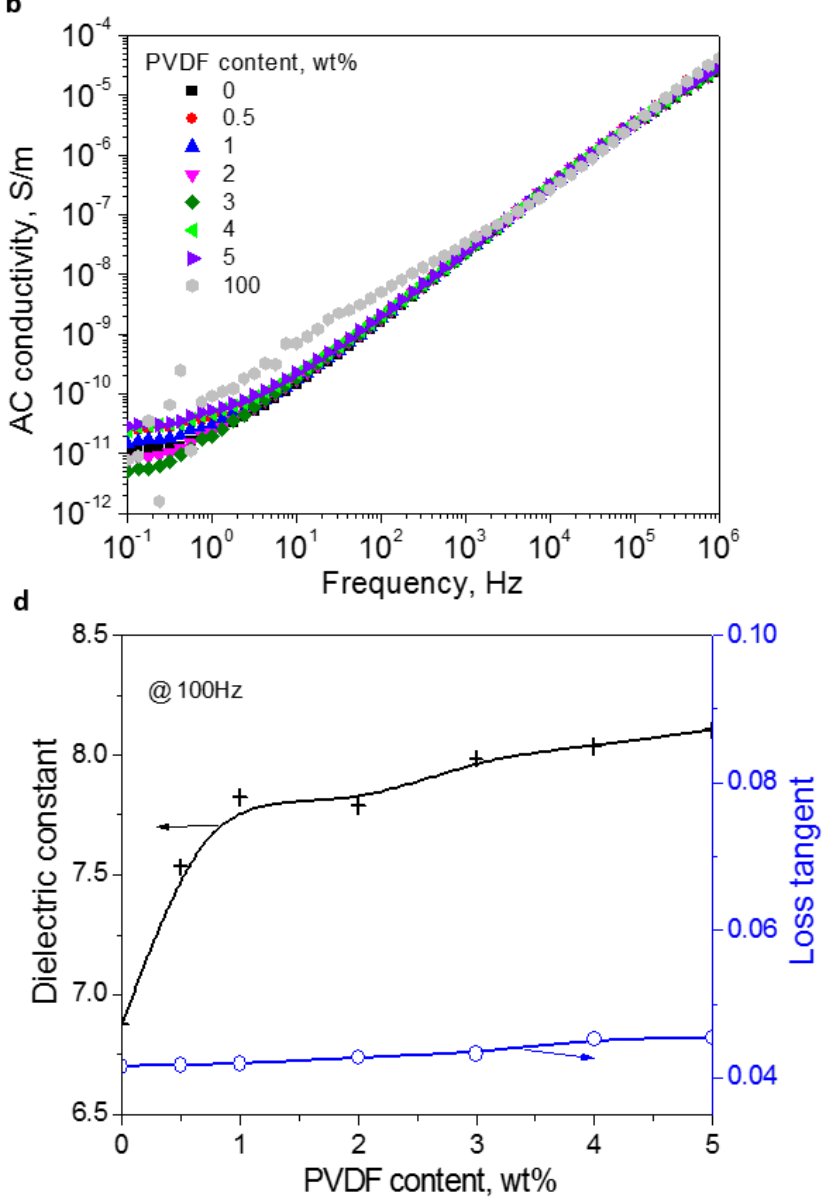

Figure 3. (a) The dielectric constant, (b) AC conductivity, and (c) loss tangent of PVDF/PVA films as a function of frequency at room temperature. (d) The dielectric constant and loss tangent at $100 \mathrm{~Hz}$ vary with PVDF nanoparticle loading.

Generally speaking, when a current flows across the two-material interfaces in a heterogeneous system, charges will accumulate at the interface between two materials with different relaxation time ( $\tau=\varepsilon / \sigma$, where $\varepsilon$ is the dielectric constant and $\sigma$ is the conductivity). ${ }^{39}$ In the present case, the relaxation time of PVDF and PVA is on the same order of magnitude. The induced interfacial polarization is actually very weak, and has a limited contribution to the improvement of dielectric constant of PVA composites. By contrast, large interface areas can be generated upon addition of even small amount of nanofillers, and induce substantial effects in polymers. We characterized the crystalline structure changes of PVA by XRD and DSC. As shown in Figure S1, PVDF nanoparticle exhibits strong nucleation ability, substantially increases the crystallinity of PVA while not impacting the size of crystallites. Intriguingly, the dielectric constant curve presented in Figure 3d resembles the crystallinity curve (Figure S1b), revealing the correlation between the crystalline structures and the dielectric constant in PVA 
films. The results suggest that the largely formed crystallites have strong dielectric response to the applied electric field owing to the spontaneous orientation of dipoles in the crystalline domains, and thus contribute predominately to the increase of dielectric constant. This mechanism is supported by the experiment results of Zhang et al. ${ }^{40}$ on poly(arylene ether urea)/alumina nanocomposites, in which 0.21 vol\% of 20-nm-sized alumina nanoparticles can lead to more than $50 \%$ increase in the dielectric constant.

Dielectric breakdown strength of PVDF/PVA nanocomposite films. For a linear dielectric, the dielectric constant is independent of the applied electric field. Consequently the energy density $U_{e}$ is linearly proportional to the production of permittivity and the square of electric field. Several reports show that the addition of high- $k$ nanoparticles can largely enhance the dielectric constant yet at the expense of the breakdown strength. ${ }^{2,14,41}$ Due to the quadratic dependence on $E_{\mathrm{b}}$, the energy density of the composites is however found to be inferior to neat polymers in spite of the improved permittivity. It is highly desirable to achieve an $E_{\mathrm{b}}$ that is superior to the neat polymers. The characteristic electric breakdown strength is generally analyzed with a two-parameter Weibull distribution function: ${ }^{42}$

$$
P(E)=1-e^{-\left(\frac{E}{E_{b}}\right)^{\beta}}
$$

where $P(E)$ is the cumulative probability of dielectric failure, $E$ is the measured breakdown strength for each specimen, $E_{b}$ is the characteristic breakdown strength that corresponds to a $\sim 63.2 \%$ probability of failure, and $\beta$ is the so-called shape parameter that evaluates the scatter of data. Herein, the $E_{b}$ and $\beta$ are calculated from a linear fitting using Weibull failure statistics (Figure 4), and the values are listed in Table 1. The high $\beta$ values indicate the structural uniformity and integrity of the investigated composite films. The $E_{\mathrm{b}}$ of pure PVDF and PVA films are 222.6 MV/m and 437.9 MV/m, respectively. It is noted that the breakdown strength of PVDF latex film is lower than that (350-400 MV/m) of typical PVDF films that are solutioncasted or melt-extruded. ${ }^{33-35,43}$ The discrepancy arises from the film processing. In the present case, the wet thin film containing suspended colloidal PVDF nanoparticles is dried on a substrate, the evaporation of water concentrates the nanoparticles into a closed packed array. The capillary pressures created by liquid menisci between colloidal particles lead to cracking of the dried film. ${ }^{5}$ Without any additive, it is difficult, if not impossible, to obtain a uniform large-area PVDF film without microcracks. It is such morphological defects that weaken the capability of the obtained dry films to sustain a high electric field. By contrast, the introduction of a small amount PVDF nanoparticles into PVA does not deteriorate but greatly promotes the 
breakdown strength of the PVA matrix. The breakdown strengths of all the polymer composites are superior to that of PVA. At an optimum PVDF content (3 wt \%), the maximum breakdown strength reaches $514.7 \mathrm{MV} / \mathrm{m}$, showing an improvement of $18 \%$. Similar enhancements have been also observed in polymer composites filled with high $k$ yet low- $E_{\mathrm{b}}$ ceramic nanofillers at low filler loadings. ${ }^{40,44-47}$ The addition of even small amount of nanofiller can chemically or physically form large-area interfaces in a nanocomposite. ${ }^{2,10,22,45,48,49}$ The dielectric properties of the interfacial regions can slightly differ from the bulk polymer matrix. ${ }^{2,50}$ They have been proven capable of suppressing space charges as deep trapping sites at high electric fields, and limit thereby the probability for breakdown. ${ }^{44,45,47}$ Actually, the breakdown strength enhances with increasing the interfacial area as a result of adding more nanoparticles. Nevertheless, beyond a certain filler content (in our case, $3 \mathrm{wt} \%$ ), the interfacial regions would percolate, and thus carriers can transport instead of being restrained in the interfacial regions. The density and mobility of carrier increases in the composites, leading to a decrement in breakdown strength ${ }^{44}$, 45, 47 (Figure 4, Table 1). Here, the effect of newly generated interfaces is also validated in a composite even composed of two polymeric phases with moderate permittivity and conductivity contrast. In addition, previous theoretic simulations ${ }^{51}$ and experiment work ${ }^{40,52}$ show that elevated crystallinity in semicrystalline polymers can substantially limit the highfield conduction losses by reducing the mean free path for the mobile charge. As compared to virgin PVA, the improved crystallinity (Figure S1B) of PVA composites should be also responsible for the augmentation of the breakdown strength. Last, it should be noted that the enhancements in the dielectric constant and breakdown field in composites with inorganic nanoparticles occur in an extremely narrow nanofiller composition range. ${ }^{40,44,47}$ By contrast, all the composites with PVDF loading ranging from $0.5 \mathrm{wt} \%$ to $5 \mathrm{wt} \%$ can exhibit improved breakdown strength as compared to the virgin PVA. This feature allows for a much broader operation window for the preparation of high- $E_{\mathrm{b}}$ PVA composites.

Table 1. The $E_{b}$ and $\beta$ of pure PVA, PVDF, and their composites at various mass ratios.

\begin{tabular}{ccc}
\hline PVDF content $(\mathrm{wt} \%)$ & $E_{\mathrm{b}}(\mathrm{MV} / \mathrm{m})$ & $\beta$ \\
\hline 0 & 437.9 & 25.2 \\
0.5 & 444.5 & 19.1 \\
1.0 & 461.5 & 15.3 \\
2.0 & 479.4 & 12.5 \\
3.0 & 514.7 & 19.5 \\
4.0 & 499.9 & 18.8 \\
5.0 & 477.8 & 15.6 \\
100 & 222.6 & 12.4 \\
\hline
\end{tabular}




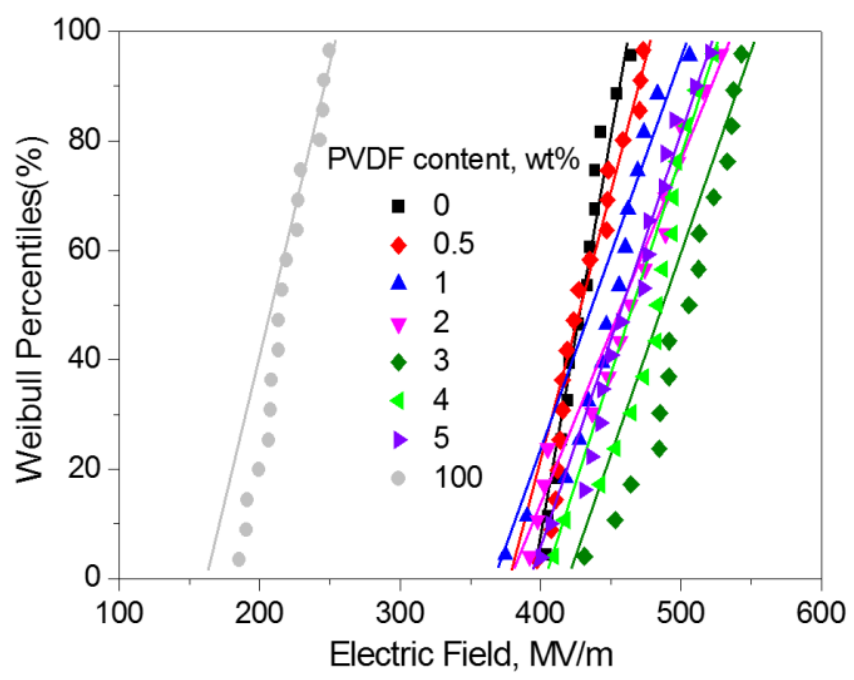

Figure 4. Failure probability of dielectric breakdown deduced from Weibull distribution for neat PVA, PVDF and their composites with various PVDF particle loadings.

High-field polarizations of PVDF/PVA nanocomposite films. We first compare the $P$ $E$ loops of different films up to a given electric field which approaches the breakdown strength of pure PVDF film. As shown in Figure 5a, being similar with the trend observed for the dielectric constant (Figure 3a), all the $P_{\max }$ of the composites fall into the interval of the two single polymer components. Nevertheless, the hysteresis loops of all the composites are much slimmer than those of pure PVDF and PVA, indicating that the introduction of PVDF nanoparticles could effectively constrain the movement of free charge carriers, resulting in reduced conduction losses at high fields. It is particularly interesting to investigate the polarizations of composite with $3 \mathrm{wt} \%$ PVDF at much higher electrical field as it shows the highest breakdown strength. With increasing the electric field, the $P_{\max }$ increases yet the composites show higher losses at higher fields (Figure 5b), which is as a result of the bulk conduction in PVA matrix. Based on the $P-E$ loops of pure PVDF, PVA, and their composites at different fields until their breakdown strength, the discharged energy density is calculated and shown in Figure 5c. Apparently, below $250 \mathrm{MV} / \mathrm{m}$, pure PVDF film shows the maximum energy density $U_{\mathrm{e}}=3.4 \mathrm{~J} / \mathrm{cm}^{3}$, while the energy densities of PVDF/PVA composites are inferior to this value but still higher than that of pure PVA film. Intriguingly, the energy density of the composite with $3 \mathrm{wt} \%$ of PVDF reaches $8.1 \mathrm{~J} / \mathrm{cm}^{3}$ at $510 \mathrm{MV} / \mathrm{m}$, which is three folds higher than that $\left(U_{\mathrm{e}}=2.4 \mathrm{~J} / \mathrm{cm}^{3}\right)$ of neat PVA, demonstrating a synergistic effect by coupling PVDF and PVA. 

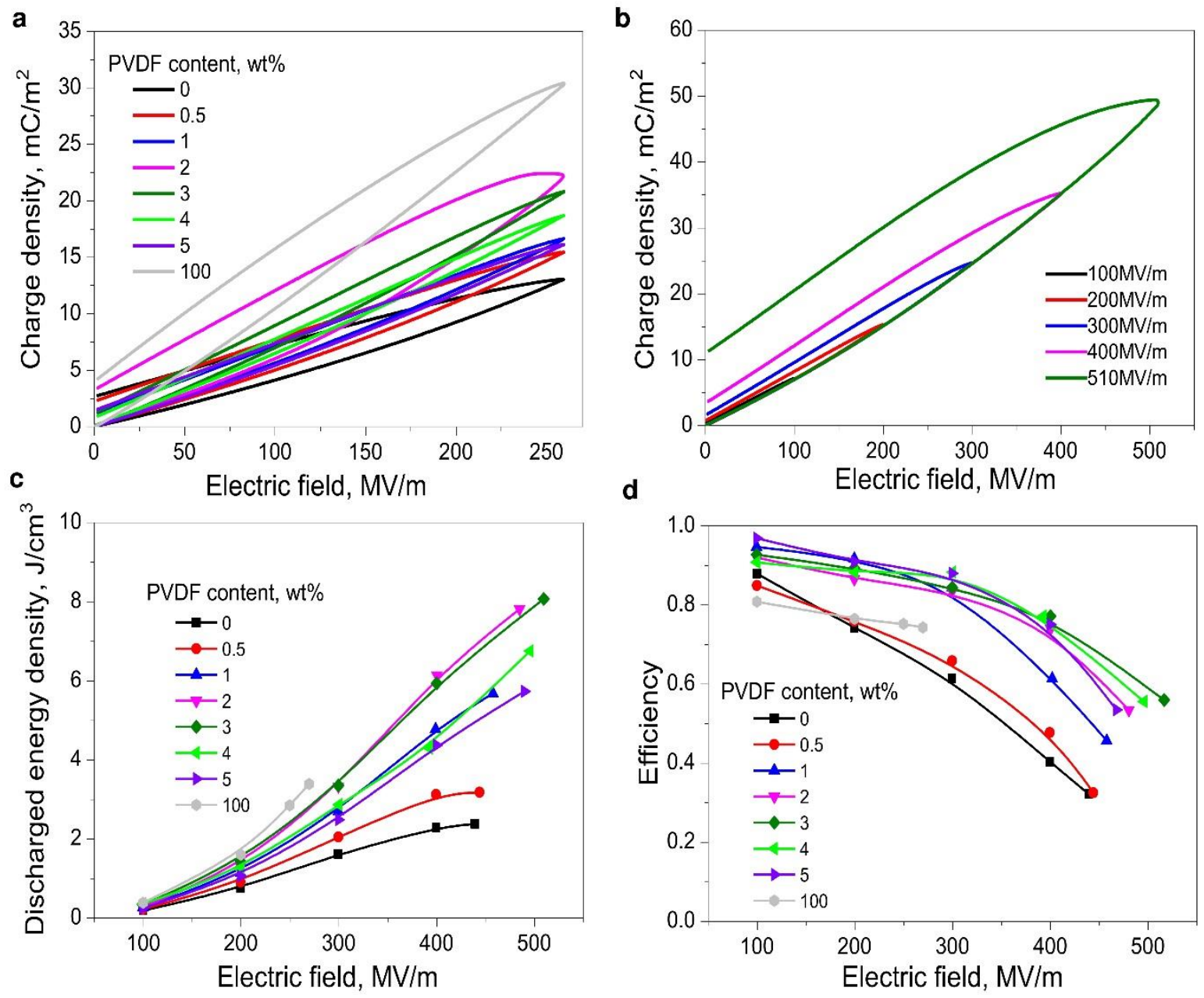

Figure 5. (a) $P-E$ loops of pure PVA, PVDF and PVDF/PVA nanocomposite films with various PVDF contents. (b) $P-E$ loops of PVA nanocomposite film with $3 \mathrm{wt} \%$ PVDF at different electric fields. (c) The discharged energy density and (d) charge/discharge efficiency as a function of electric field for pure PVA, PVDF, and PVDF/PVA nanocomposite films.

For practical applications, it is also important to evaluate the charge/discharge efficiency, $\eta$, which is defined as

$$
\eta=\frac{U_{e}}{U_{s}}=1-\frac{U_{l}}{U_{s}}
$$

where $U_{s}, U_{e}$, and $U_{l}$ are the stored, discharged energy and energy loss, respectively. $U_{l}$ is calculated by the numerical integration of the closed area of the hysteresis $P-E$ loops. As shown in Figure 5d, the efficiency of all the films decreases with the applied electric field, because of the more pronounced conduction losses at higher fields. It is clearly shown that the efficiency is enhanced with the introduction of PVDF nanoparticles as compared to neat PVA film. This is another evidence for the charge carrier constraint as a result of the incorporation of small amount of PVDF nanoparticles. Consequently, at the maximum electric field, the efficiency of $3 \mathrm{wt} \%$ nanocomposite is about 0.6 , higher than that $(\sim 0.3)$ of neat PVA. The energy storage 
performances of pure PVA and its composites have been summarized and shown in Figure 6. The overall desirable high-field properties demonstrate great potential of PVDF/PVA composites for the dielectric energy storage applications. The maximum breakdown strength of PVDF/PVA composites can compare with most of previously reported polymeric dielectric materials, as listed in Table 2. The improvement of energy density (defined as $U_{\mathrm{e}} / U_{\mathrm{m}}$, where $U_{\mathrm{m}}$ is the discharged energy density of base materials) is much higher than those of the reported polymeric dielectrics. The charge/discharge efficiency $(60 \%)$ is relatively lower than the counterparts. However, it should be noted that most of the polymeric dielectrics are either meltextruded at high temperatures or solution-processed in harmful organic solvents. Our strategy relies on environmental benign processes, has great promise for the "green" manufacturing of next-generation polymeric dielectrics.

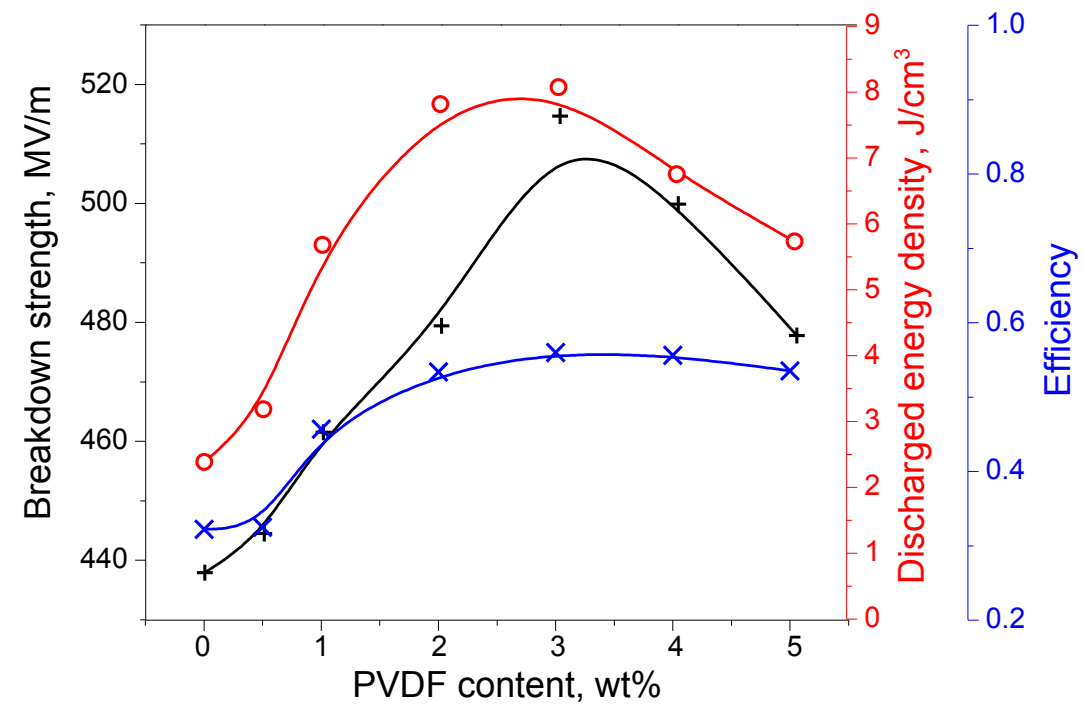

Figure 6. The breakdown strength, discharged energy density, and charge/discharge efficiency as a function of PVDF content for the PVDF/PVA composite films. The discharged energy density and the charge/discharge efficiency were measured at the maximum electrical field that they can sustain before electrical breakdown. 
Table 2. Comparison of the energy storage performances of different polymeric dielectric materials.

\begin{tabular}{|c|c|c|c|c|c|}
\hline Materials & Processing methods & $\begin{array}{c}E_{\mathbf{b}} \\
\mathrm{MV} / \mathrm{m}\end{array}$ & $\underset{\mathrm{J} / \mathrm{cm}^{3}}{U_{\mathrm{e}}}$ & $\boldsymbol{U}_{\mathrm{e}} / \boldsymbol{U}_{\mathbf{m}}$ & $\eta$ \\
\hline MBS/PVDF ${ }^{33 a}$ & solution casting in $\mathrm{DMF}^{j}$ & 535 & 9.8 & 2.2 & $62 \%$ \\
\hline TPU/PVDF ${ }^{35 b}$ & solution casting in DMF & 538 & 10.4 & 2.3 & $\mathrm{n} / \mathrm{a}$ \\
\hline PET/PVDF ${ }^{34}$ & $\begin{array}{l}\text { melt-mixing and hot- } \\
\text { pressing }\end{array}$ & 453 & 7 & 1.6 & $\mathrm{n} / \mathrm{a}$ \\
\hline $\mathrm{P}(\mathrm{VDF}-\mathrm{TrFE}-\mathrm{CFE}) / \mathrm{PVDF}^{53 c}$ & solution casting in DMF & 665 & 19.6 & 1.6 & $\mathrm{n} / \mathrm{a}$ \\
\hline $\begin{array}{c}\text { PET/PMMA/P(VDF-HFP) } \\
\text { multilayer film } 38 d\end{array}$ & melt coextruding & 1000 & 17.4 & 1.5 & $\mathrm{n} / \mathrm{a}$ \\
\hline PC/PVDF layered film ${ }^{37}$ & melt coextruding & 650 & 11 & 1.8 & $60 \%$ \\
\hline $\mathrm{P}(\mathrm{VDF}-\mathrm{HFP}) / \mathrm{PMMA}^{31 e}$ & solution casting in $\mathrm{DMAC}^{k}$ & 475 & 11.2 & 2.6 & $86 \%$ \\
\hline $\begin{array}{l}\text { P(VDF-CTFE)- } g \text {-PS } \\
\text { copolymer }^{54 f}\end{array}$ & $\begin{array}{c}\text { grafting copolymerization } \\
\text { and solution casting in } \\
\mathrm{THF}^{l}\end{array}$ & 520 & 12 & 1.2 & $70 \%$ \\
\hline $\begin{array}{l}\text { P(VDF-TrFE-CTFE)- } g \text { - } \\
\text { PMMA copolymer }{ }^{55} g\end{array}$ & $\begin{array}{c}\text { grafting copolymerization } \\
\text { and solution casting in } \\
\text { DMF }\end{array}$ & 500 & 10.5 & 2.6 & $70 \%$ \\
\hline $\begin{array}{l}\text { Bis(double-stranded) Block } \\
\text { Copolymer }^{56}\end{array}$ & $\begin{array}{l}\text { tandem metathesis } \\
\text { polymerization and solution } \\
\text { casting in organic solvents }\end{array}$ & 370 & 9.9 & $\mathrm{n} / \mathrm{a}$ & $84 \%$ \\
\hline PMGS-ArTU $57 h$ & $\begin{array}{l}\text { polymerization and solution } \\
\text { casting in DMF }\end{array}$ & 419 & 3.2 & $\mathrm{n} / \mathrm{a}$ & $87 \%$ \\
\hline $\mathrm{c}-\mathrm{BCB} / \mathrm{BNNS}^{8 \mathrm{i}}$ & $\begin{array}{l}\text { drop casting from } \mathrm{DMM}^{m} \\
\text { solution and thermally } \\
\text { crosslinking }\end{array}$ & 447 & 2.5 & $\mathrm{n} / \mathrm{a}$ & $95 \%$ \\
\hline $\begin{array}{c}\mathrm{BaTiO}_{3} @ \mathrm{TiO}_{2} / \mathrm{P}(\mathrm{VDF}- \\
\mathrm{HFP})^{58}\end{array}$ & solution casting in DMF & 500 & 9.95 & 1.3 & $65 \%$ \\
\hline PVDF latex/PVA & water-based process & 514 & 8.1 & 3.4 & $60 \%$ \\
\hline
\end{tabular}

${ }^{a}$ Methyl methacrylate-butadiene-styrene/PVDF. ${ }^{b}$ Thermoplastic polyurethane/PVDF. ${ }^{c}$ Polyvinylidene fluoride-trifluoroethylene-chlorofluoroethylene/PVDF. ${ }^{d}$ Poly(ethylene terephthalate)/poly(methyl methacrylate)/poly(vinylidene fluoride-co-hexafluoropropylene). ${ }^{e}$ Poly(vinylidene fluoridehexafluoropropylene)/poly(methylmethacrylate). ${ }^{f}$ Poly(vinylidene fluoride-co-chlorotrifluoroethylene)-graft-polystyrene. ${ }^{g}$ poly(vinylidene fluoride-cotrifluoroethylene-co-chlorotrifluoroethylene)-graft-poly(methyl methacrylate). ${ }^{h}$ Cross-linked polysiloxane-aromatic thiourea. ${ }^{i}$ crosslinked divinyltetramethyldisiloxanebis(benzocyclobutene)/boron nitride nanosheets. ${ }^{j} \mathrm{~N}, \mathrm{~N}$-Dimethylformamide. ${ }^{k}$ Dimethylacetamide. ${ }^{l}$ Tetrahydrofuran. ${ }^{m}$ Dipropylene glycol dimethyl ether. 
In addition to the high energy density, power energy storage requires a fast discharge rate. ${ }^{15,16,59}$ We used a high-speed capacitor discharge circuit (Figure 7a) with a high-voltage MOSFET (metal oxide semiconductor field effect transistor) switch to measure the discharge speed of the nanocomposite with 3\%wt PVDF and commercial BOPP film. Both samples were first charged at $200 \mathrm{MV} / \mathrm{m}$, followed by discharging across a $10 \mathrm{k} \Omega$ load resistor in series with the polymer capacitor. The discharging curves are shown in Figure $7 \mathbf{b}$. The voltage, $U(\mathrm{t})$, across the load resistor, $R_{\mathrm{L}}$, decreases exponentially with time. The fitting to the curves by the equation $U(t)=U_{0} e^{-(t / \tau)}$ yields the time constant, $\tau$. For the waterborne nanocomposite (Figure S2a-c), obtained $\tau$ varies from $0.40 \mu$ s to $0.63 \mu$ s as broadening the fitting time range. Likewise, $\tau$ of BOPP film capacitor varies from $0.38 \mu$ s to $0.65 \mu$ s (Figure S2d-f). Both sample capacitors have nearly identical time constant for a given fitting time range, which actually allows for fairly comparing their power densities. Furthermore, the deduced $R_{\mathrm{L}} C$ values are $0.59 \mu$ s and $0.45 \mu$ s for waterborne nanocomposite and BOPP films respectively. Both of them fall in the range of $\tau$ yielded by fitting. The change of $\tau$ obtained from the fitting to different time ranges can be associated to the increased effect of equivalent series resistor (ESR) of samples at later discharge process. ${ }^{16}$ Based on the discharging curves, the instant power $P_{\mathrm{e}}$ can be calculated by ${ }^{16}$

$$
P_{e}=\frac{U(t)^{2}}{R_{L}}
$$

The discharged energy density $U_{e}$ of the dielectric material is further calculated by ${ }^{16}$

$$
U_{e}=\frac{\int_{0}^{\infty} P_{e} d t}{V}=\frac{\int_{0}^{\infty} \frac{U(t)^{2}}{R_{L}} d t}{V}
$$

where $V$ is the volume of dielectric materials. The calculated energy density is plotted in Figure 7c as a function of time. The discharge time is defined here as the time that is needed to reach $95 \%$ of the final discharge energy in a load resistor. ${ }^{60}$ In this regard, the nanocomposite releases a stored energy of $1.329 \mathrm{~J} / \mathrm{cm}^{3}$ at a rate of $1.172 \mu \mathrm{s}$, while the rate for BOPP is $1.168 \mu \mathrm{s}$ for releasing a stored energy of $0.299 \mathrm{~J} / \mathrm{cm}^{3}$. Accordingly, the waterborne nanocomposite shows a superior power density of $1.13 \mathrm{MW} / \mathrm{cm}^{3}$ to that of BOPP $\left(0.26 \mathrm{MW} / \mathrm{cm}^{3}\right)$. The cyclic charge/discharge was performed on both samples under an applied field of $200 \mathrm{MV} / \mathrm{m}$ to evaluate the stability of the materials. As shown in Figure 7d, there is not degradation over 1000 cycles of charge/discharge of the waterborne nanocomposite with $3 \mathrm{wt} \%$ PVDF. 
a

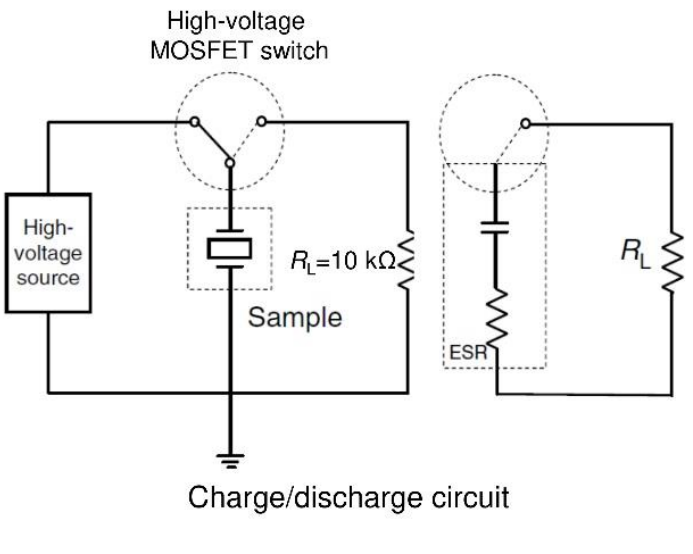

c

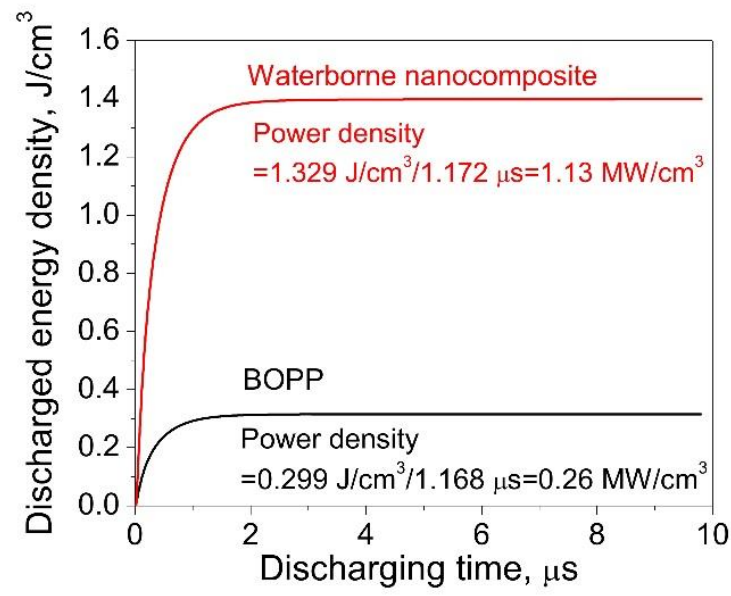

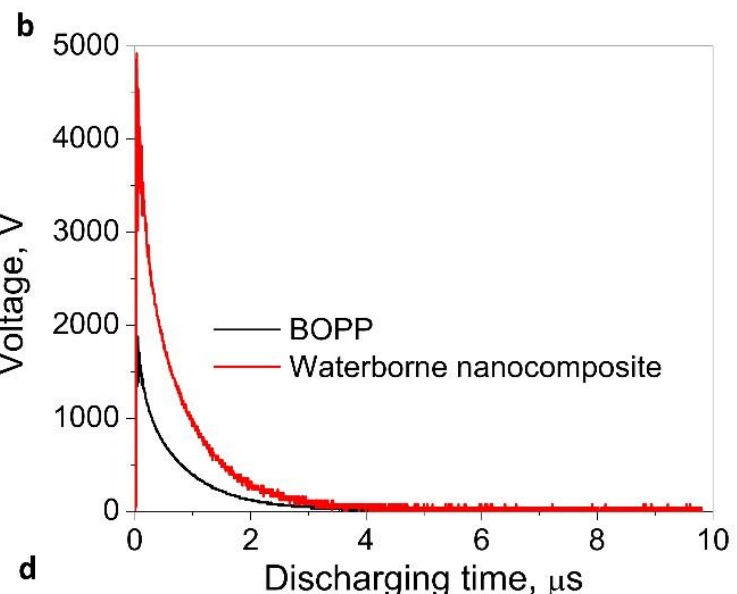

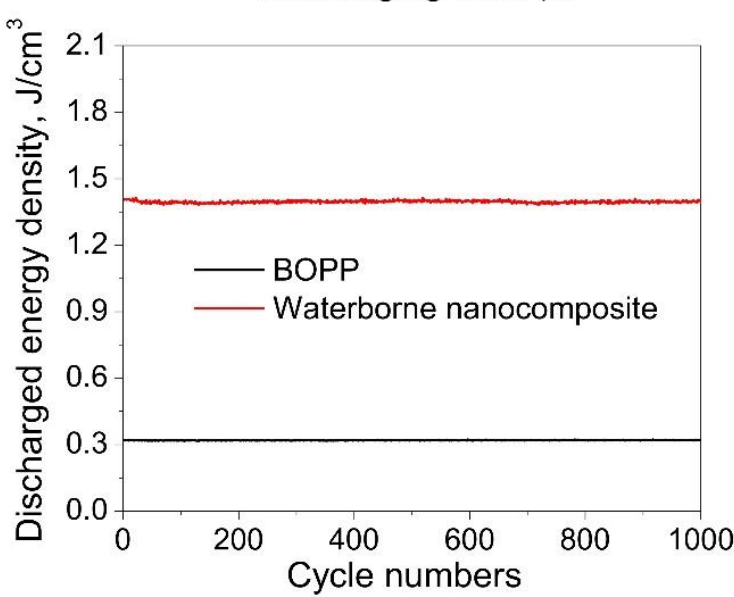

Figure 7. (a) Circuit diagram of the charge/discharge experiment operated with a high-voltage MOSFET switch. The losses of samples are treated as an ESR. The voltage (b) and discharged energy density (c) as a function of time. The BOPP and waterborne nanocomposite films ( $3 \mathrm{wt} \%$ of PVDF) have respectively a thickness of $9.8 \mu \mathrm{m}$ and $24 \mu \mathrm{m}$, which correspond to capacitance of $45 \mathrm{pF}$ and $59 \mathrm{pF}$ respectively. (d) Cyclic charge/discharge performances of both samples under electric field of $200 \mathrm{MV} / \mathrm{m}$.

\section{CONCLUSION}

In summary, waterborne polymer nanocomposites are prepared by mixing low-cost PVDF latex and water soluble polymer PVA, followed by a solution-casting method. Compared with pure PVA film, the dielectric response of waterborne nanocomposites is improved because of the formation of more crystallites in PVA matrix as a result of the introduction of a small amount of PVDF latex nanoparticles. Moreover, due to the charge carrier constraint effect associate to the newly generated large-area interfaces, the nanocomposite with an optimum PVDF contents (3\%) shows a breakdown strength as high as $515 \mathrm{MV} / \mathrm{m}$ and an energy density of $8.1 \mathrm{~J} / \mathrm{cm}^{3}$, which respectively show improvements by $18 \%$ and $238 \%$ as compared to pure PVA film. The waterborne nanocomposites with a microsecond discharge rate exhibit a power 
density on the level of $1.1 \mathrm{MW} / \mathrm{cm}^{3}$. It is anticipated that this work opens an environmentally begin route to boost the energy storage performances of polymer nanocomposites.

\section{ASSOCIATED CONTENT}

\section{Supporting Information}

The Supporting Information is available free of charge at https://pubs.acs.org/.

DSC curves and XRD patterns of pure PVA and its composites with various PVDF loadings; The degree of crystallinity and estimated size of crystallites of PVA as a function of PVDF loading; Fitting of the discharging voltage as a function of time for capacitors based on waterborne nanocomposite as well as commercial BOPP film.

\section{AUTHOR INFORMATION}

\section{Corresponding Author}

Jinkai Yuan-- Centre de Recherche Paul Pascal, CNRS, Université de Bordeaux, 115 Avenue Schweitzer, 33600 Pessac, France. Email : jinkai.yuan@crpp.cnrs.fr.

\section{Authors}

Junjin Che-- Centre de Recherche Paul Pascal, CNRS, Université de Bordeaux, 115 Avenue Schweitzer, 33600 Pessac, France

Wilfrid Neri-- Centre de Recherche Paul Pascal, CNRS, Université de Bordeaux, 115 Avenue Schweitzer, 33600 Pessac, France

Isabelle Ly-- Centre de Recherche Paul Pascal, CNRS, Université de Bordeaux, 115 Avenue Schweitzer, 33600 Pessac, France

Philippe Poulin-- Centre de Recherche Paul Pascal, CNRS, Université de Bordeaux, 115 Avenue Schweitzer, 33600 Pessac, France

Cécile Zakri-- Centre de Recherche Paul Pascal, CNRS, Université de Bordeaux, 115 Avenue Schweitzer, 33600 Pessac, France

\section{Notes}

The authors declare no competing financial interest. 


\section{ACKNOWLEDGMENTS}

This work was partially funded by the CNRS Energy unit (Cellule Energie) through the project MicroPower. J. Che thanks the financial support from Chinese Scholarship Council (201806240088). Mr A. Bentaleb is gratefully acknowledged for his help on the wide-angle xray diffraction characterizations.

\section{REFERENCES}

1. Simon, P.; Gogotsi, Y. Materials for Electrochemical Capacitors. Nat. Mater. 2008, 7, 845854.

2. Dang, Z.M.; Yuan, J.K.; Yao, S.H.; Liao, R.J. Flexible Nanodielectric Materials with High Permittivity for Power Energy Storage. Adv. Mater. 2013, 25, 6334-6365.

3. Gur, T. M. Review of Electrical Energy Storage Technologies, Materials and Systems: Challenges and Prospects for Large-Scale Grid Storage. Energy Environ. Sci. 2018, 11, 2696-2767.

4. Pan, H.; Ma, J.; Zhang, Q. H.; Liu, X. Z.; Guan, B.; Gu, L.; Zhang, X.; Zhang, Y. J.; Li, L. L.; Shen, Y.; Lin, Y. H.; Nan, C. W. Giant Energy Density and High Efficiency Achieved in Bismuth Ferrite-Based Film Capacitors via Domain Engineering. Nat. Commun. 2018, 9, 1813.

5. Torres-Canas, F.; Yuan, J.; Ly, I.; Neri, W.; Colin, A.; Poulin, P. Inkjet Printing of LatexBased High-Energy Microcapacitors. Adv. Funct. Mater. 2019, 29, 1901884.

6. Riggs, B. C.; Elupula, R.; Grayson, S. M.; Chrisey, D. B. Photonic Curing of Aromatic Thiol-Ene Click Dielectric Capacitors via Inkjet Printing. J. Mater. Chem. A. 2014, 2 , 17380-17386.

7. Riggs, B. C.; Elupula, R.; Rehm, C.; Adireddy, S.; Grayson, S. M.; Chrisey, D. B. Clickin Ferroelectric Nanoparticles for Dielectric Energy Storage. ACS Appl. Mater. Interfaces 2015, 7, 17819-17825.

8. Li, Q.; Chen, L.; Gadinski, M. R.; Zhang, S. H.; Zhang, G. Z.; Li, H. Y.; Haque, A.; Chen, L. Q.; Jackson, T. N.; Wang, Q. Flexible High-Temperature Dielectric Materials From Polymer Nanocomposites. Nature. 2015, 523, 576-579.

9. Zhang, X.; Shen, Y.; Xu, B.; Zhang, Q. H.; Gu, L.; Jiang, J. Y.; Ma, J.; Lin, Y. H.; Nan, C. W. Giant Energy Density and Improved Discharge Efficiency of SolutionProcessed Polymer Nanocomposites for Dielectric Energy Storage. Adv. Mater. 2016, 28, 2055-2061. 
10. Chen, Q.; Shen, Y.; Zhang, S. H.; Zhang, Q. M. Polymer-Based Dielectrics with High Energy Storage Density. Annu. Rev. Mater. Sci. 2015, 45, 433-458.

11. Huan, T. D.; Boggs, S.; Teyssedre, G.; Laurent, C.; Cakmak, M.; Kumar, S.; Ramprasad, R. Advanced Polymeric Dielectrics for High Energy Density Applications. Prog. Mater. Sci. 2016, 83, 236-269.

12. Luna, A.; Yuan, J.; Neri, W.; Zakri, C.; Poulin, P.; Colin, A. Giant Permittivity Polymer Nanocomposites Obtained by Curing a Direct Emulsion. Langmuir. 2015, 31, 1223112239.

13. Yuan, J. K.; Yao, S. H.; Li, W. L.; Sylvestre, A.; Bai, J. B. Anisotropic Percolation of SiC-Carbon Nanotube Hybrids: A New Route Toward Thermally Conductive High- $k$ Polymer Composites. J. Phys. Chem. C. 2017, 121, 12063-12070.

14. Fan, B. H.; Zhou, M. Y.; Zhang, C.; He, D. L.; Bai, J. B. Polymer-Based Materials for Achieving High Energy Density Film Capacitors. Prog. Polym. Sci. 2019, 97, 101143.

15. Wang, Y.; Zhou, X.; Chen, Q.; Chu, B.; Zhang, Q. Recent Development of High Energy Density Polymers for Dielectric Capacitors. IEEE Trans. Dielectr. Electr. Insul. 2010, 17, 1036-1042.

16. Chu, B.; Zhou, X.; Ren, K.; Neese, B.; Lin, M.; Wang, Q.; Bauer, F.; Zhang, Q. M. A Dielectric Polymer with High Electric Energy Density And Fast Discharge Speed. Science. 2006, 313, 334-336.

17. Zhang, Q. M.; Bharti, V.; Zhao, X. Giant Electrostriction and Relaxor Ferroelectric Behavior in Electron-Irradiated Poly(vinylidene fluoride-trifluoroethylene) Copolymer. Science. 1998, 280, 2101-2104.

18. Xia, F.; Cheng, Z. Y.; Xu, H. S.; Li, H. F.; Zhang, Q. M.; Kavarnos, G. J.; Ting, R. Y.; Abdul-Sedat, G.; Belfield, K. D. High Electromechanical Responses in A Poly(vinylidene fluoride-trifluoroethylene-chlorofluoroethylene) Terpolymer. Adv. Mater. 2002, 14, 15741577.

19. Yuan, J. K.; Luna, A.; Neri, W.; Zakri, C.; Schilling, T.; Colin, A.; Poulin, P. Graphene Liquid Crystal Retarded Percolation for New High- $k$ Materials. Nat. Commun. 2015, 6, 8700 .

20. Yuan, J.; Luna, A.; Neri, R.; Zakri, C.; Colin, A.; Poulin, P. Giant Electrostriction of Soft Nanocomposites Based on Liquid Crystalline Graphene. ACS Nano 2018, 12, 16881695.

21. Huang, X.; Jiang, P. Core-Shell Structured High- $k$ Polymer Nanocomposites for Energy Storage And Dielectric Applications. Adv. Mater. 2015, 27, 546-554. 
22. Luo, H.; Zhou, X. F.; Ellingford, C.; Zhang, Y.; Chen, S.; Zhou, K. C.; Zhang, D.; Bowen, C. R.; Wan, C. Y. Interface Design for High Energy Density Polymer Nanocomposites. Chem. Soc. Rev. 2019, 48, 4424-4465.

23. Zhang, X.; Li, B. W.; Dong, L. J.; Liu, H. X.; Chen, W.; Shen, Y.; Nan, C. W. Superior Energy Storage Performances of Polymer Nanocomposites via Modification of Filler/Polymer Interfaces. Adv. Mater. Interfaces 2018, 5, 1800096.

24. Niu, Y. J.; Wang, H., Dielectric Nanomaterials for Power Energy Storage: Surface Modification And Characterization. ACS Appl. Nano Mater. 2019, 2, 627-642.

25. Seiler, J.; Kindersberger, J., Insight Into The Interphase in Polymer Nanocomposites. IEEE Trans. Dielectr. Electr. Insul. 2014, 21, 537-547.

26. Pan, Z. B.; Yao, L. M.; Zhai, J. W.; Yao, X.; Chen, H., Interfacial Coupling Effect in Organic/Inorganic Nanocomposites with High Energy Density. Adv. Mater. 2018, 30, 1705662.

27. Tang, H. X.; Lin, Y. R.; Sodano, H. A. Synthesis of High Aspect Ratio $\mathrm{BaTiO}_{3} \mathrm{Nanowires}$ for High Energy Density Nanocomposite Capacitors. Adv. Energy Mater. 2013, 3, 451-456.

28. Zhu, Y. K.; Zhu, Y. J.; Huang, X. Y.; Chen, J.; Li, Q.; He, J. L.; Jiang, P. K. High Energy Density Polymer Dielectrics Interlayered by Assembled Boron Nitride Nanosheets. Adv. Energy. Mater. 2019, 9, 1901826.

29. Guo, M. F.; Jiang, J. Y.; Shen, Z. H.; Lin, Y. H.; Nan, C. W.; Shen, Y. High-EnergyDensity Ferroelectric Polymer Nanocomposites for Capacitive Energy Storage: Enhanced Breakdown Strength and Improved Discharge Efficiency. Mater. Today 2019, 29, 49-67.

30. Baer, E.; Zhu, L. 50th Anniversary Perspective: Dielectric Phenomena in Polymers and Multilayered Dielectric Films. Macromolecules. 2017, 50, 2239-2256.

31. Luo, B. C.; Wang, X. H.; Wang, H. X.; Cai, Z. M.; Li, L. T. P(VDF-HFP)/PMMA Flexible Composite Films with Enhanced Energy Storage Density and Efficiency. Compos. Sci. Technol. 2017, 151, 94-103.

32. Jiang, J. Y.; Shen, Z. H.; Qian, J. F.; Dan, Z. K.; Guo, M. F.; Lin, Y. H.; Nan, C. W.; Chen, L. Q.; Shen, Y. Ultrahigh Discharge Efficiency in Multilayered Polymer Nanocomposites of High Energy Density. Energy Storage Mater. 2019, 18, 213-221.

33. Zheng, M. S.; Zha, J. W.; Yang, Y.; Han, P.; Hu, C. H.; Dang, Z. M. Enhanced Breakdown Strength of Poly(vinylidene fluoride) Utilizing Rubber Nanoparticles for Energy Storage Application. Appl. Phys. Lett. 2016, 109, 072902. 
34. Yao, L.; Wang, D. R.; Hu, P. H.; Han, B. Z.; Dang, Z. M. Synergetic Enhancement of Permittivity and Breakdown Strength in All-Polymeric Dielectrics Toward Flexible Energy Storage Devices. Adv. Mater. Interfaces 2016, 3, 1600016.

35. Zheng, M. S.; Zha, J. W.; Yang, Y.; Han, P.; Hu, C. H.; Wen, Y. Q.; Dang, Z. M. Polyurethane Induced High Breakdown Strength And High Energy Storage Density in Polyurethane/Poly(vinylidene fluoride) Composite Films. Appl. Phys. Lett. 2017, 110, 252902.

36. Wolak, M. A.; Pan, M.-J.; Wan, A.; Shirk, J. S.; Mackey, M.; Hiltner, A.; Baer, E.; Flandin, L. Dielectric Response of Structured Multilayered Polymer Films Fabricated by Forced Assembly. Appl. Phys. Lett. 2008, 92, 113301.

37. Mackey, M.; Schuele, D. E.; Zhu, L.; Flandin, L.; Wolak, M. A.; Shirk, J. S.; Hiltner, A.; Baer, E. Reduction of Dielectric Hysteresis in Multi Layered Films via Nanoconfinement. Macromolecules. 2012, 45, 1954-1962.

38. Yin, K. Z.; Zhou, Z.; Schuele, D. E.; Wolak, M.; Zhu, L.; Baer, E. Effects of Interphase Modification And Biaxial Orientation on Dielectric Properties of Poly(ethylene terephthalate)/Poly(vinylidene fluoride-co-hexafluoropropylene) Multilayer Films. ACS Appl. Mater. Interfaces 2016, 8, 13555-13566.

39. Yuan, J.K.; Yao, S.H.; Dang, Z.M.; Sylvestre, A.; Genestoux, M.; Bai, J., Giant Dielectric Permittivity Nanocomposites: Realizing True Potential of Pristine Carbon Nanotubes in Polyvinylidene Fluoride Matrix Through An Enhanced Interfacial Interaction. J. Phys. Chem. C 2011, 115, 5515-5521.

40. Zhang, T.; Chen, X.; Thakur, Y.; Lu, B.; Zhang, Q. Y.; Runt, J.; Zhang, Q. M., A Highly Scalable Dielectric Metamaterial with Superior Capacitor Performance Over A Broad Temperature. Sci. Adv. 2020, 6, eaax6622.

41. Roscow, J. I.; Bowen, C. R.; Almond, D. P. Breakdown in The Case for Materials with Giant Permittivity? ACS Energy Lett. 2017, 2, 2264-2269.

42. Claude, J.; Lu, Y.; Wanga, Q. Effect of Molecular Weight On The Dielectric Breakdown Strength of Ferroelectric Poly(vinylidene fluoride-chlorotrifluoroethylene)s. Appl. Phys. Lett. 2007, 91, 211901.

43. Fan, B. H.; Xing, Z. L.; Bedoui, F.; Yuan, J. K.; Lu, X. X.; He, D. L.; Zhou, M. Y.; Zhang, C.; Dang, Z. M.; Weigand, S.; Bai, J. B., Improving Dielectric Strength of Polyvinylidene Fluoride by Blending Chains with Different Molecular Weights. Polymer 2020, 190, 122235. 
44. Ding, S. J.; Yu, S. H.; Zhu, X. D.; Xie, S. H.; Sun, R.; Liao, W. H.; Wong, C. P. Enhanced Breakdown Strength of Polymer Composites by Low Filler Loading And Its Mechanisms. Appl. Phys. Lett. 2017, 111, 153902.

45. Li, S. T.; Yin, G. L.; Bai, S. N.; Li, J. Y. A New Potential Barrier Model in Epoxy Resin Nanodielectrics. IEEE Trans. Dielectr. Electr. Insul. 2011, 18, 1535-1543.

46. Shen, Z. H.; Wang, J. J.; Lin, Y. H.; Nan, C. W.; Chen, L. Q.; Shen, Y. High-Throughput Phase-Field Design of High-Energy-Density Polymer Nanocomposites. Adv. Mater. 2018, $30,1704380$.

47. Lu, Y.C.; Yu, S.; Zeng, X.; Sun, R.; Wong, C.P. High Energy Density Polymer Nanocomposites with Y-Doped Barium Strontium Titanate Nanoparticles As Fillers. IET Nanodielectr. 2018, 1, 137-142.

48. Shen, Y.; Lin, Y. H.; Zhang, Q. M. Polymer Nanocomposites with High Energy Storage Densities. MRS Bull. 2015, 40, 753-759.

49. Li, S.; Yin, G.; Chen, G.; Li, J.; Bai, S.; Zhong, L.; Zhang, Y.; Lei, Q. Short-Term Breakdown And Long-Term Failure in Nanodielectrics: A Review. IEEE Trans. Dielectr. Electr. Insul. 2010, 17, 1523-1535.

50. Thakur, Y.; Zhang, T.; Iacob, C.; Yang, T. N.; Bernholc, J.; Chen, L. Q.; Runt, J.; Zhang, Q. M., Enhancement of The Dielectric Response in Polymer Nanocomposites with Low Dielectric Constant Fillers. Nanoscale 2017, 9, 10992-10997.

51. Xu, C.; Zheng, Z.; Boggs, S. A., Simulation of High Field Resistive and Absorption Currents in Semicrystalline Polymer Films. Coference Record of the 2006 IEEE International Symposium on Electrical Insulation, 2006, 358-361.

52. Zhang, L.; Zhang, Y. X.; Zhou, Y. X.; Teng, C. Y.; Peng, Z. W.; Spinella, S., Crystalline Modification And Its Effects On Dielectric Breakdown Strength And Space Charge Behavior in Isotactic Polypropylene. Polymers 2018, 10, 406.

53. Zhang, X.; Shen, Y.; Shen, Z. H.; Jiang, J. Y.; Chen, L. Q.; Nan, C. W., Achieving High Energy Density in PVDF-Based Polymer Blends: Suppression of Early Polarization Saturation and Enhancement of Breakdown Strength. ACS Appl. Mater. Interfaces 2016, $8,27236-27242$

54. Guan, F. X.; Yang, L. Y.; Wang, J.; Guan, B.; Han, K.; Wang, Q.; Zhu, L., Confined Ferroelectric Properties in Poly(vinylidene fluoride-co-chlorotrifluoroethylene)-GraftPolystyrene Graft Copolymers for Electric Energy Storage Applications. Adv. Funct. Mater. 2011, 21 (16), 3176-3188. 
55. Li, J. J.; Hu, X.; Gao, G. X.; Ding, S. J.; Li, H. Y.; Yang, L. J.; Zhang, Z. C., Tuning Phase Transition And Ferroelectric Properties of Poly(vinylidene fluoride-cotrifluoroethylene) Via Grafting With Desired Poly(methacrylic ester)s As Side Chains. $J$. Mater. Chem. C 2013, 1, 1111-1121.

56. Chen, J.; Wang, Y. X.; Li, H. F.; Han, H. J.; Liao, X. J.; Sun, R. Y.; Huang, X. Y.; Xie, M. R., Rational Design And Modification of High- $k$ Bis(double-stranded) Block Copolymer for High Electrical Energy Storage Capability. Chem. Mater. 2018, 30, $1102-$ 1112.

57. Liu, Y.; Chen, J.; Jiang , X.; Jiang, P.; Huang, X., All-Organic Cross-Linked Polysiloxane-Aromatic Thiourea Dielectric Films for Electrical Energy Storage Application. ACS Appl. Energy Mater. 2020, 3, 5198-5207.

58. Kang, D.; Wang, G. Y.; Huang, Y. H.; Jiang, P. K.; Huang, X. Y., Decorating $\mathrm{TiO}_{2}$ Nanowires With $\mathrm{BaTiO}_{3}$ Nanoparticles: A New Approach Leading To Substantially Enhanced Energy Storage Capability of High-k Polymer Nanocomposites. ACS Appl. Mater. Interfaces 2018, 10, 4077-4085.

59. Zhou, X.; Chu, B.; Neese, B.; Lin, M.; Zhang, Q. M. Electrical Energy Density And Discharge Characteristics of A Poly(vinylidene fluoride-chlorotrifluoroethylene) Copolymer. IEEE Trans. Dielectr. Electr. Insul. 2007, 14, 1133-1138.

60. Khanchaitit, P.; Han, K.; Gadinski, M. R.; Li, Q.; Wang, Q. Ferroelectric Polymer Networks With High Energy Density And Improved Discharged Efficiency for Dielectric Energy Storage. Nat.Commun. 2013, 4, 2845. 


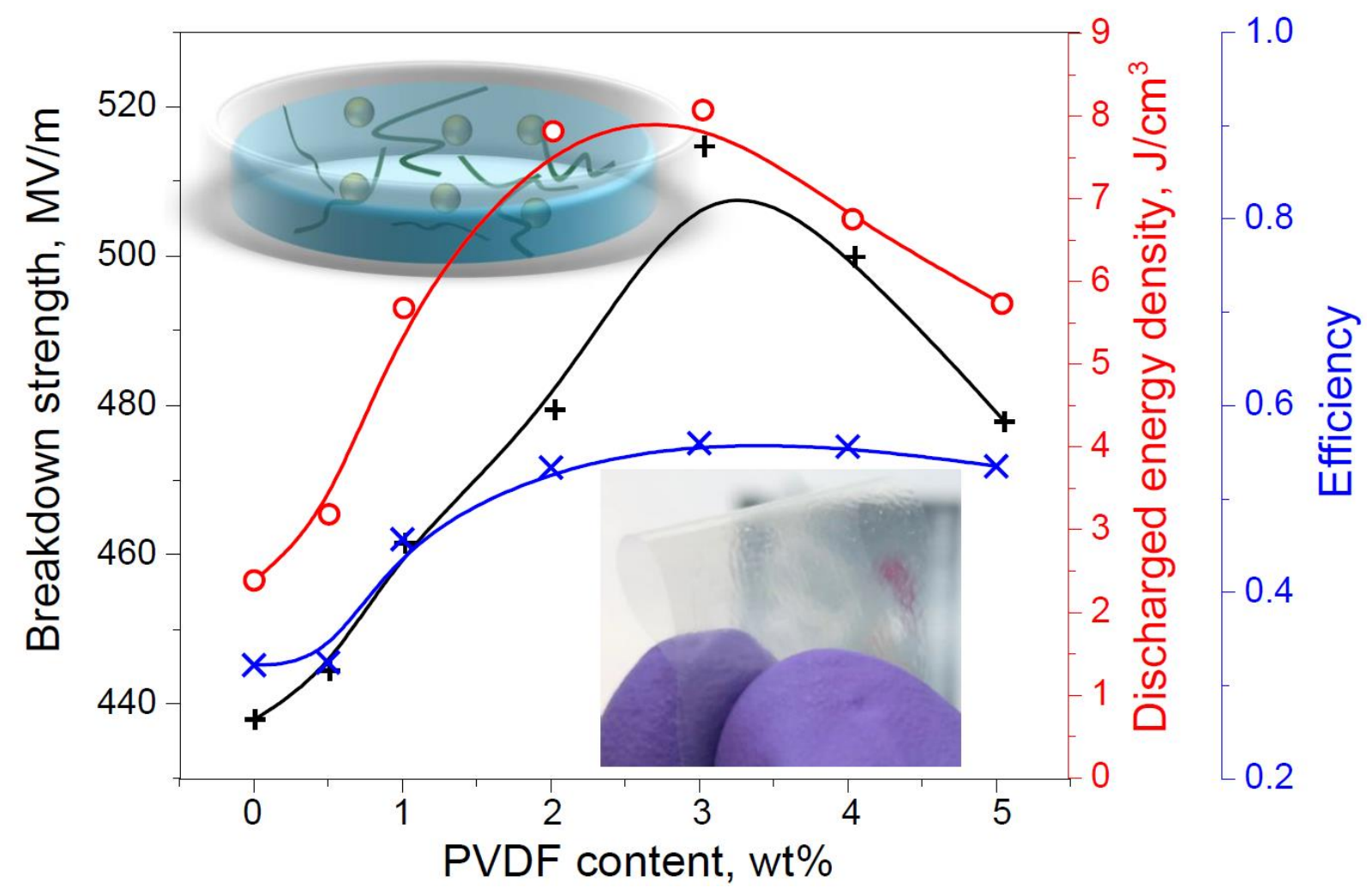

TOC 


\title{
Waterborne Nanocomposites with Enhanced Breakdown Strength for High Energy Storage
}

\author{
Junjin Che, Wilfrid Neri, Isabelle Ly, Philippe Poulin
}

Cécile Zakri, Jinkai Yuan*

Centre de Recherche Paul Pascal, CNRS, Université de Bordeaux, 115 Avenue Schweitzer, 33600 Pessac, France

*Correspondance to: jinkai.yuan@crpp.cnrs.fr

\section{Supplementary Figures}


a

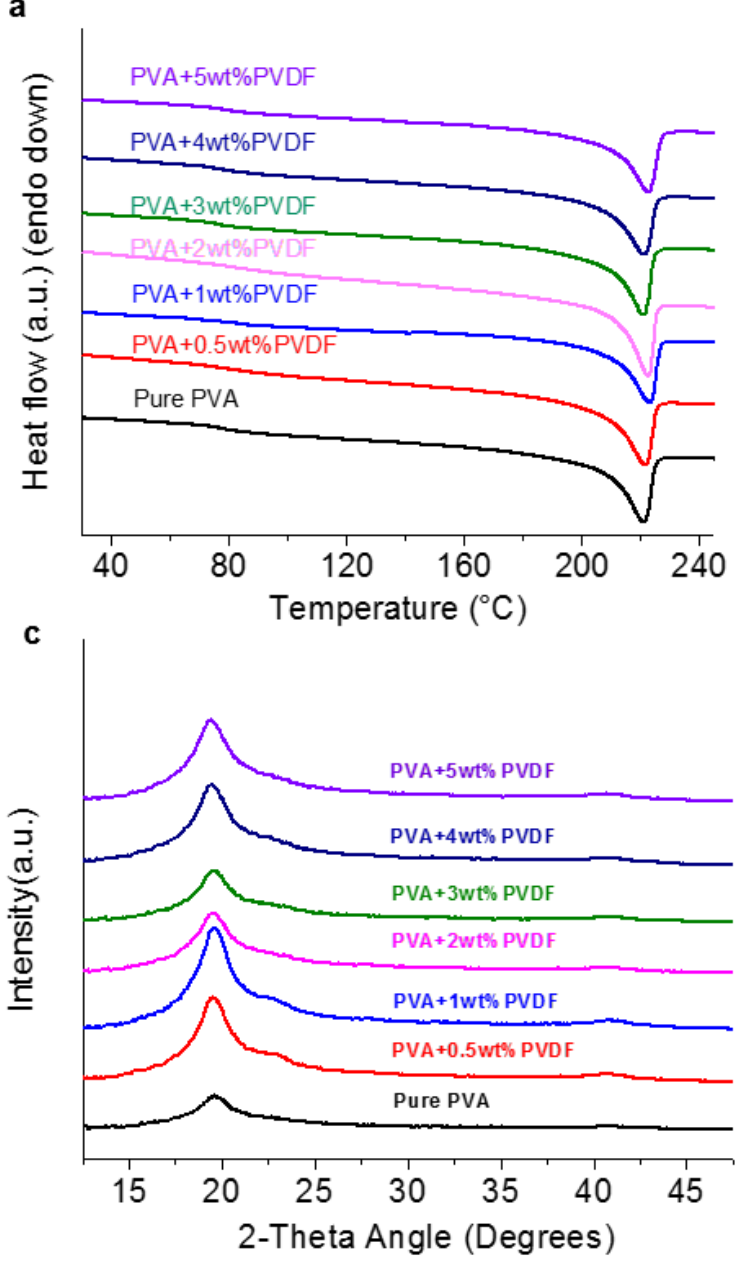

b
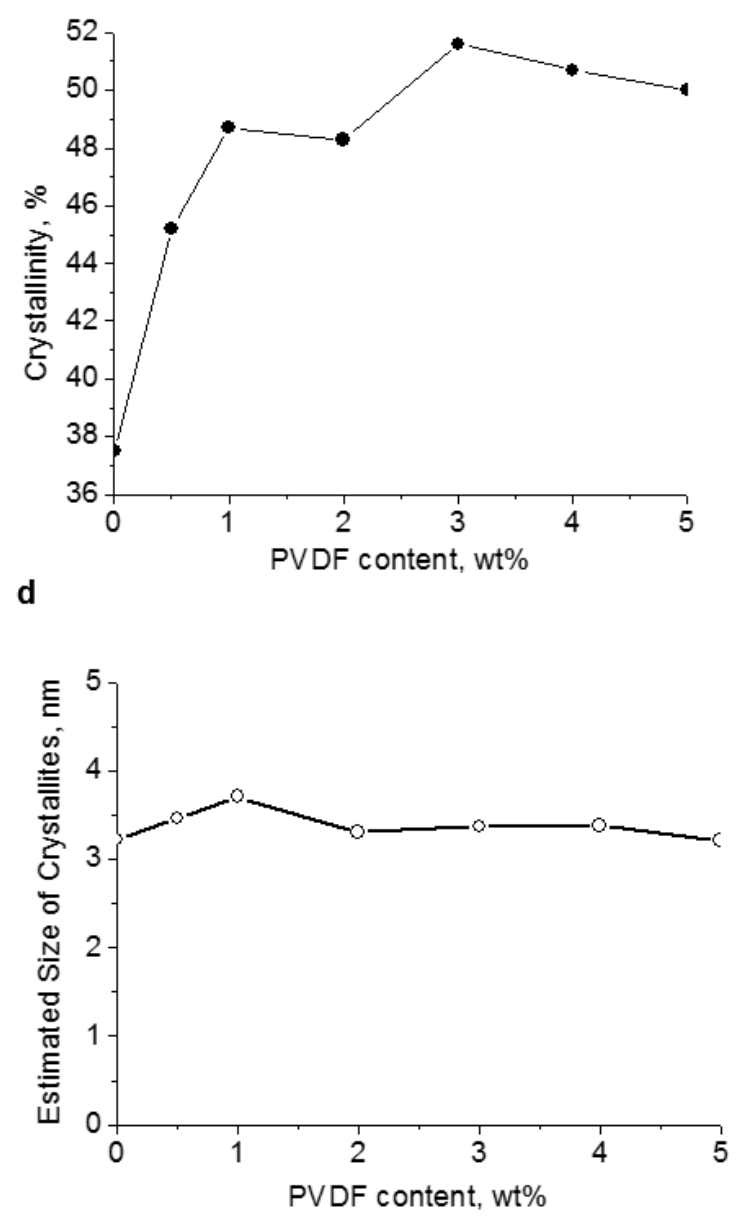

Figure S1. (a) DSC curves and (c) XRD patterns of pure PVA and its composites with various PVDF loadings. (b)The degree of crystallinity as a function of PVDF loading. The crystallinity of samples is determined by evaluating the enthalpy of fusion and comparing it to the enthalpy of fusion of $100 \%$ crystalline PVA. The calorimetric crystalline is defined as $X_{\mathrm{c}}(\%)=\left[\Delta H_{\mathrm{c}} /((1-\right.$ $\left.\left.\Phi) \cdot \Delta H_{\mathrm{m}}\right)\right] \times 100 . X_{\mathrm{c}}$ is the weight fraction of crystallinity, $\Phi$ is weight fraction of PVDF, $\Delta H_{\mathrm{c}}$ is the enthalpy of fusion at the melting point for each sample, $\Delta H_{\mathrm{m}}$ is the enthalpy of fusion of the totally crystalline polymer measured at the equilibrium melting point and equal to $138.6 \mathrm{~J} / \mathrm{g}$ for PVA. (d) Estimated size of crystallites of PVA as a function of PVDF loading. The average size of crystallites is estimated from Scherrer equation, $D=K \lambda / B \cos \theta$, where $D$ is the mean size of the crystalline domains. $K$ is the shape factor, which has a typical value of about 0.9. $\lambda$ is the $\mathrm{X}$-ray wavelength $(0.15418 \mathrm{~nm}$ in our case $) . B$ is line broadening at half the maximum intensity (FWHM, in radians). $\theta$ is the Bragg angle in radians. 

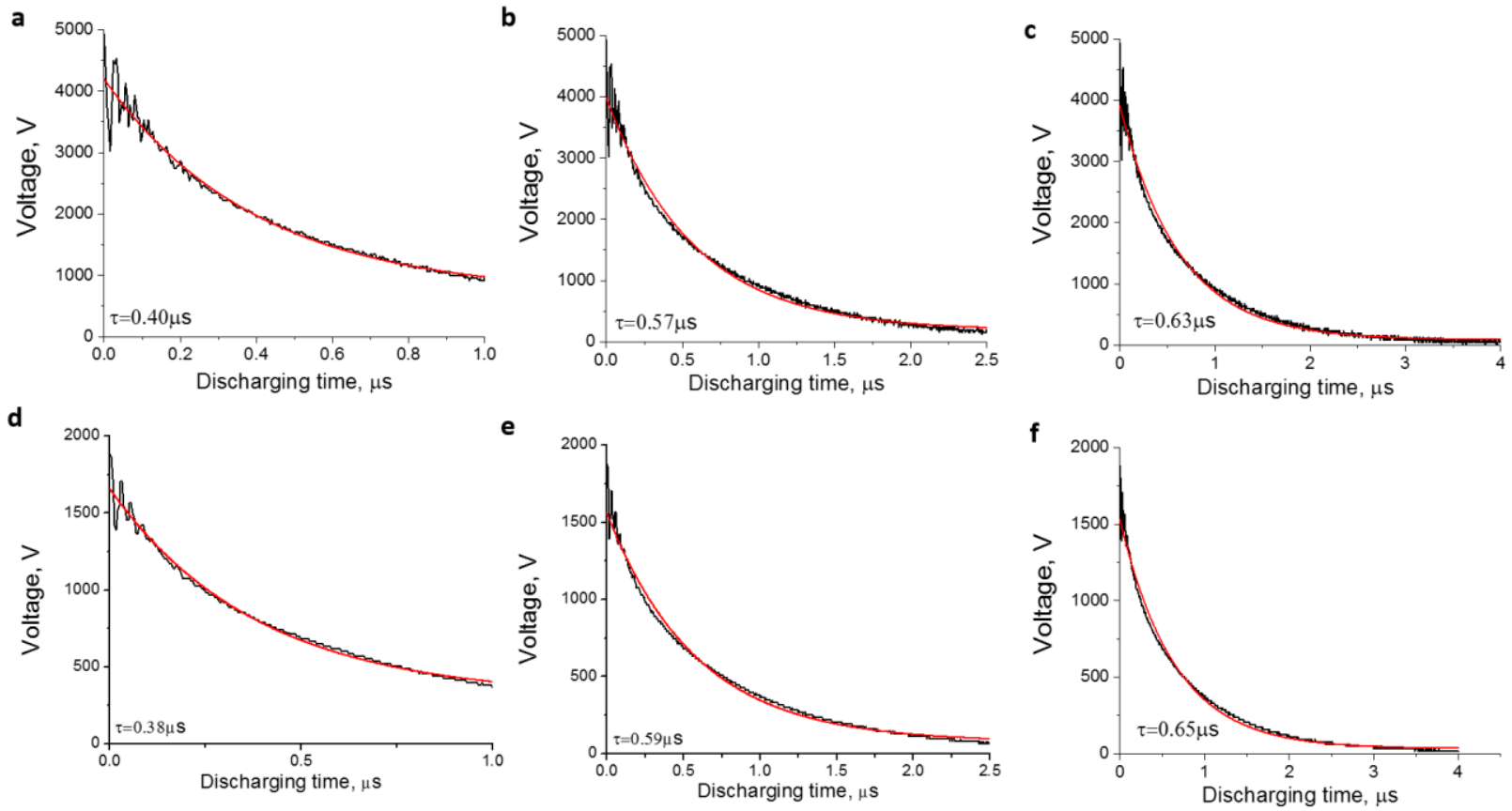

Figure S2. Fitting of the discharging voltage as a function of time for (a-c) waterborne nanocomposite as well as (d-f) commercial BOPP film. The $\tau$ yielded from the fitting is indicated in the figure. Red curves are the fitting and black curves are the experimental data. The BOPP and waterborne nanocomposite films (3 wt\% of PVDF) have respectively a thickness of $9.8 \mu \mathrm{m}$ and $24 \mu \mathrm{m}$, which correspond to capacitance of $45 \mathrm{pF}$ and $59 \mathrm{pF}$ respectively. 